\title{
Activation of pentafluoropropane isomers at a nanoscopic aluminum chlorofluoride: hydrodefluorination versus dehydrofluorination
}

\author{
Maëva-Charlotte Kervarec, Thomas Braun", Mike Ahrens and Erhard Kemnitz
}

\author{
Full Research Paper \\ Address: \\ Department of Chemistry, Humboldt-Universität zu Berlin, \\ Brook-Taylor-Straße 2, 12489 Berlin, Germany \\ Email: \\ Thomas Braun* - thomas.braun@cms.hu-berlin.de \\ * Corresponding author \\ Keywords: \\ aluminum fluoride; C-F bond activation; dehydrofluorination; \\ hydrodefluorination; hydrofluorocarbons
}

\author{
Beilstein J. Org. Chem. 2020, 16, 2623-2635. \\ https://doi.org/10.3762/bjoc.16.213 \\ Received: 27 July 2020 \\ Accepted: 09 October 2020 \\ Published: 23 October 2020 \\ This article is part of the thematic issue "Organo-fluorine chemistry V". \\ Guest Editor: D. O'Hagan \\ (C) 2020 Kervarec et al.; licensee Beilstein-Institut. \\ License and terms: see end of document.
}

\begin{abstract}
The hydrofluorocarbon 245 isomers, 1,1,1,3,3-pentafluoropropane, 1,1,1,2,2- pentafluoropropane, and 1,1,1,2,3-pentafluoropropane (HFC-245fa, HFC-245cb, and HFC-245eb) were activated through C-F bond activations using aluminium chlorofluoride (ACF) as a catalyst. The addition of the hydrogen source $\mathrm{Et}_{3} \mathrm{SiH}$ is necessary for the activation of the secondary and tertiary $\mathrm{C}-\mathrm{F}$ bonds. Multiple C-F bond activations such as hydrodefluorinations and dehydrofluorinations were observed, followed by hydroarylation and Friedel-Crafts-type reactions under mild conditions.
\end{abstract}

\section{Introduction}

Hydrofluorocarbons (HFCs) have been intensively used in daily life, mainly due to their excellent properties in refrigeration applications [1-3]. In the past, HFCs were considered as replacements that do not deplete ozone for chlorofluorocarbons (CFCs) and hydrochlorofluorocarbons (HCFCs), which have been strictly regulated by the Montreal protocol [4-6]. However, due to the high global warming potential (GWP), HFCs have also been included in the Montreal protocol in 2019 (Kigali amendment) and have to be phased out [7-10].

On the other hand, HFCs are valuable starting compounds or intermediate products for the synthesis of hydrofluoroolefins
(HFOs), which have been regarded as the next generation of refrigerants, exhibiting zero ozone depletion potential (ODP) and a negligible GWP [11-13]. A considerable amount of studies has been carried out to synthesize HFOs under mild conditions [11,14-16]. Among them are routes to access 2,3,3,3tetrafluoropropene and 1,3,3,3-tetrafluoropropene (HFO-1234yf and HFO-1234ze), for which numerous patents suggest synthetic pathways and showcase the reactivity $[12,13,15]$. One possibility for the preparation includes the conversion of pentafluoropropanes (HFC-245 isomers) using chromia-based catalysts, or metal chloride/fluoride $\left(\mathrm{AlF}_{3}, \mathrm{MgF}_{2}\right)$-supported catalysts at elevated temperatures $\left(350^{\circ} \mathrm{C}\right)[11,14,15,17,18]$. The group of 
Lu recently reported the gas-phase transformation of 1,1,1,3,3pentafluoropropane (HFC-245eb) into 1,3,3,3-tetrafluoropropene (HFO-1234ze) using mesoporous nanoscopic aluminum fluoride-based catalysts [19]. The catalysts were prepared via a sol-gel process in the presence of polyols, allowing for the evolution of a large surface area and improved acidic properties when compared to fluorinated $\mathrm{Cr}_{2} \mathrm{O}_{3}$ or traditional $\beta-\mathrm{AlF}_{3}$ catalysts. At a reaction temperature set at $280{ }^{\circ} \mathrm{C}$, the conversion of 1,1,1,2,2- pentafluoropropane (HFC-245fa) into the 1,3,3,3tetrafluoropropene (HFO-1234ze) varied between 50 and $60 \%$, depending on the conditions used to synthesize the catalyst, reaching almost full selectivity. The harsh conditions are in part needed due to the high dissociation energy of $\mathrm{C}-\mathrm{F}$ bonds, and in general, $\mathrm{C}-\mathrm{F}$ activation steps are considered to be challenging [20-27].

Solid Lewis acids with a high fluoride ion affinity as catalysts are useful tools for $\mathrm{C}-\mathrm{F}$ bond activation reactions since the Lewis acidic centers can induce dehydrofluorination reactions, involving the abstraction of a fluoride ion by heterolytic bond cleavage [28-31]. $\mathrm{AlF}_{3}$-based catalysts are among the strongest Lewis acidic materials. They exhibit an effective activity in $\mathrm{C}-\mathrm{F}$ bond conversion reactions and are widely investigated [16,28,32-39]. Especially microporous aluminum chlorofluoride ( $\mathrm{ACF}, \mathrm{AlCl}_{\mathrm{x}} \mathrm{F}_{3-x} ; x=0.05-0.3$ ), which has a large surface area $\left(>200 \mathrm{~m}^{2} \mathrm{~g}^{-1}\right)$ and was patented by Dupont in 1992, has been extensively studied [40-46]. It is an amorphous aluminum fluoride doped with chlorine atoms which causes a distortion of the structure resulting in the amorphicity and high Lewis acidity of the compound. The reactivity of ACF towards $\mathrm{C}-\mathrm{F}$ bond ac- tivations was deeply investigated. For instance, the activation of fluoromethanes was observed at $\mathrm{ACF}$ in the presence of $\mathrm{HSiEt}_{3}$ as a hydrogen source to produce, in the presence of benzene as the solvent, Friedel-Crafts products as main compounds [47]. In contrast, the hydrodefluorination products were generated in the absence of benzene. Thermodynamically, the generation of strong $\mathrm{H}-\mathrm{F}, \mathrm{Al}-\mathrm{F}$, or $\mathrm{Si}-\mathrm{F}$ bonds can enforce an activation of $\mathrm{C}-\mathrm{F}$ bonds under mild conditions, and hence the addition of the silane $\mathrm{HSiEt}_{3}$ as a hydrogen source [27,48,49]. More recently, ACF was shown to efficiently convert the fluoroalkenes HFO1234yf (1) and HFO-1234ze (4a) in the presence of the hydrogen source $\mathrm{HSiEt}_{3}$ into the hydrodefluorination or Friedel-Crafts products (Scheme 1) [16].

The activation of fluoropentane was achieved using a modified ACF, loaded with germane or silane [39]. When silane was immobilized at the surface of ACF in the presence of benzene, Friedel-Crafts products were again generated. In comparison, when ACF was loaded with germane, dehydrofluorination products were detected. Besides, 2-chloro-1,1,1,2-tetrafluoropropane (HCFC-244bb) was as well effectively activated at ACF to yield the corresponding dehydrofluorination product 2-chloro-3,3,3-trifluoropropene (HFO-1233xf) without the use of any additional hydrogen source [50]. In the presence of silane and ACF, HFO-1233xf was further activated via allylic hydrodefluorination.

In this paper, we report on the reactivity of ACF towards hydrofluorocarbons, and in particular, the pentafluoropropane isomers (HFC-245). Effective hydrodefluorination and dehydrofluorina-

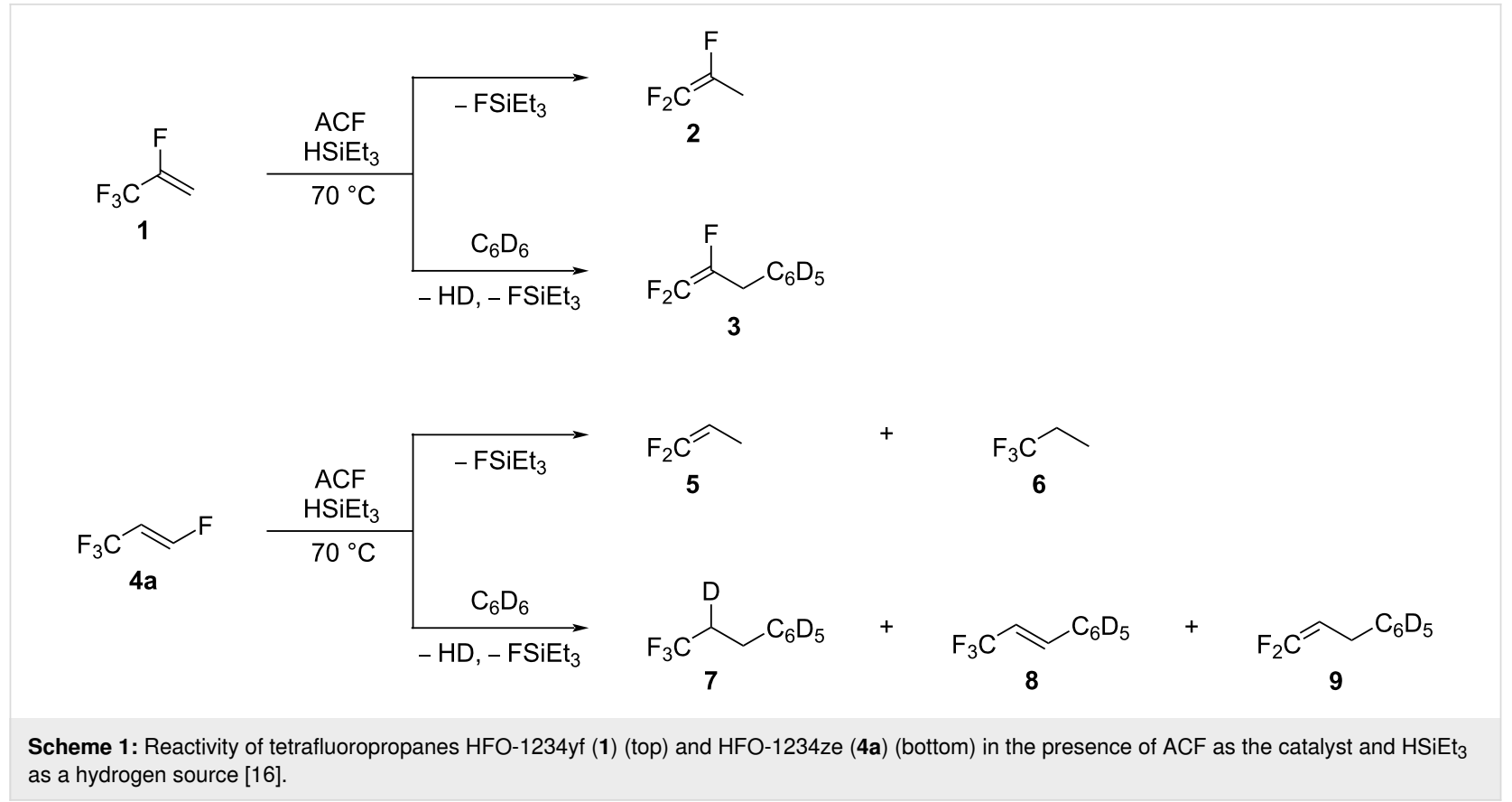


tion steps of pentafluoropropane isomers in the presence of $\mathrm{Et}_{3} \mathrm{SiH}$ as a hydrogen source at mild conditions are described.

\section{Results and Discussion Activation of 1,1,1,2,3-pentafluoropropane (HFC-245eb, 10a)}

The treatment of 1,1,1,2,3-pentafluoropropane (10a) with ACF at $70{ }^{\circ} \mathrm{C}$ in $\mathrm{C}_{6} \mathrm{D}_{12}$ gave the dehydrofluorination product $2,3,3,3$ tetrafluoropropene (HFO-1234yf, 1) and the isomerization product 1,1,1,2,2-pentafluoropropane (HFC-245cb, 10b) in a $1: 2$ ratio (Scheme 2, top) with almost full conversion. The group of Kemnitz previously showed that $\mathbf{1}$ and $\mathbf{1 0 b}$ can be in an equilibrium when $\mathrm{HF}$ is present in the reaction mixture [33]. It was demonstrated that starting from 2-chloro-3,3,3-trifluoropropene (HFO-1233xf) in the presence of fluorinated $\mathrm{Cr}_{2} \mathrm{O}_{3}$ as a catalyst and HF, 2,3,3,3-tetrafluoropropene (HFO-1234yf, 1) is generated by the replacement of the chlorine substituent with a fluorine atom, and is further transformed by $\mathrm{HF}$ addition into 1,1,1,2,2-pentafluoropropane (HFC-245cb, 10b) [33].

When the aromatic solvent $\mathrm{C}_{6} \mathrm{D}_{6}$ was used instead of $\mathrm{C}_{6} \mathrm{D}_{12}$, 10a was once more transformed into $\mathbf{1}$ as the main compound, together with traces of the Friedel-Crafts product $\mathrm{CF}_{3} \mathrm{CFHCH}_{2} \mathrm{C}_{6} \mathrm{D}_{5}$ (11) and the hydroarylation product $\mathrm{CF}_{3} \mathrm{CFDCH}_{2} \mathrm{C}_{6} \mathrm{D}_{5}$ (12) (Scheme 2, bottom), with only $22 \%$ conversion. The low conversion in $\mathrm{C}_{6} \mathrm{D}_{6}$ could be a consequence of a possible interaction of the aromatic solvent with the surface of ACF, which would result in the blocking of the acidic sites, and thus hamper the adsorption of the substrates. Indeed, in a previous study, a pulse TA experiment suggested the presence of a strong interaction between benzene and the surface of ACF [38]. This result was further confirmed by ${ }^{1} \mathrm{H}$ MAS NMR spectroscopy.

Note, that 10a was activated under mild conditions without the use of an additional hydrogen source, which often has been added for the activation of $\mathrm{C}-\mathrm{F}$ bonds at ACF $[16,39,47]$.
Several patents cover the transformation of $\mathbf{1 0 a}$ by dehydrofluorination at chromia-based catalysts, but the reaction temperatures were above $200{ }^{\circ} \mathrm{C}[17,51,52]$.

Mechanistically, an abstraction of a fluorine from the $\mathrm{CH}_{2} \mathrm{~F}$ group by the surface of ACF can occur, generating carbeniumlike species and surface fluorides (Scheme 3). Via HF elimination, the olefin 1 can be produced, followed by a refluorination of the double bond by the released HF, generating $\mathbf{1 0 b}$ (Scheme 3 , left). In the presence of $\mathrm{C}_{6} \mathrm{D}_{6}$, the hydroarylation product 12 can be generated from $\mathbf{1}$ at the ACF surface. Alternatively, the aromatic solvent can also attack the carbenium-like species, producing a zwitterionic Wheeland intermediate, which can release the Friedel-Crafts product $\mathbf{1 1}$ and DF to regenerate the catalyst (Scheme 3, right).

Although a hydrogen source was not needed to accomplish the activation of $10 a$, it was of interest to introduce a silane, because as mentioned above, recent reports showed that the activation of various substrates treated with ACF was indeed promoted by the presence of silanes $[16,39,47]$. Thus, the experiments were also conducted in the presence of $\mathrm{HSiEt}_{3}$, either in a solvent $\left(\mathrm{C}_{6} \mathrm{D}_{6}\right.$ or $\left.\mathrm{C}_{6} \mathrm{D}_{12}\right)$, or in neat silane under similar conditions (all reactions were carried out at $70{ }^{\circ} \mathrm{C}$ and monitored for 7 days).

The treatment of 10a and $\mathrm{HSiEt}_{3}$ in $\mathrm{C}_{6} \mathrm{D}_{12}$ generated $\mathbf{1}$ and $\mathbf{1 0 b}$ again, in addition to traces of 1,1,2-trifluoropropene (2, Scheme 4, top). The ratio between the olefin 1 and the refluorination product $\mathbf{1 0 b}$ observed in the presence of $\mathrm{HSiEt}_{3}$ was $3: 1$, whereas, without the silane, a ratio of 1:2 was detected. This difference in the ratio might relate to the amount of HF present in the reaction mixture, which would be lower in the presence of silane because the latter can convert with HF into fluorosilane and $\mathrm{H}_{2}[39,50,53]$. Consequently, less refluorination takes place, and a higher selectivity towards the formation of the olefin 1 is observed. In $\mathrm{C}_{6} \mathrm{D}_{6}$, the activation of 10a gave comparable results as when no $\mathrm{HSiEt}_{3}$ was introduced (Scheme 4,

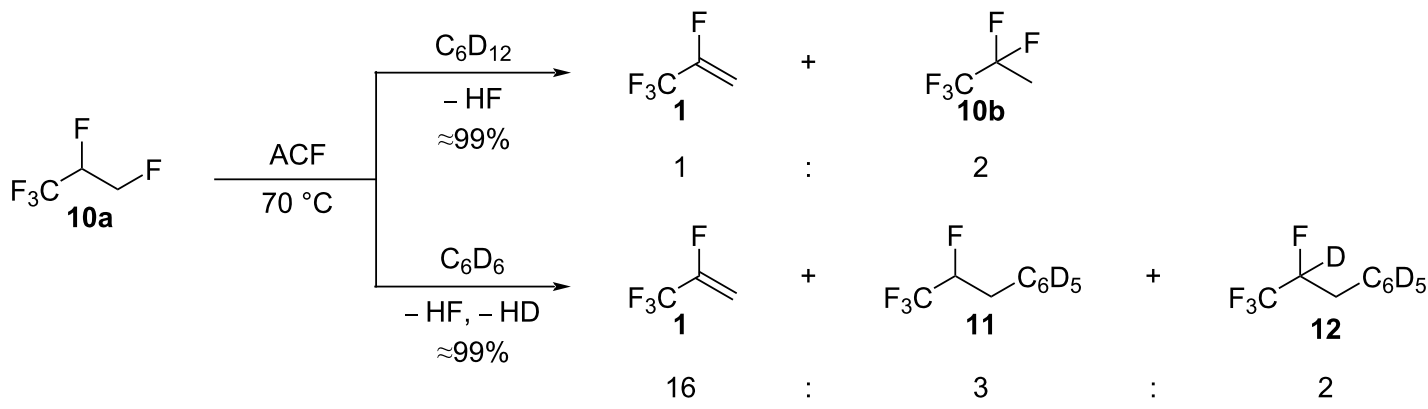




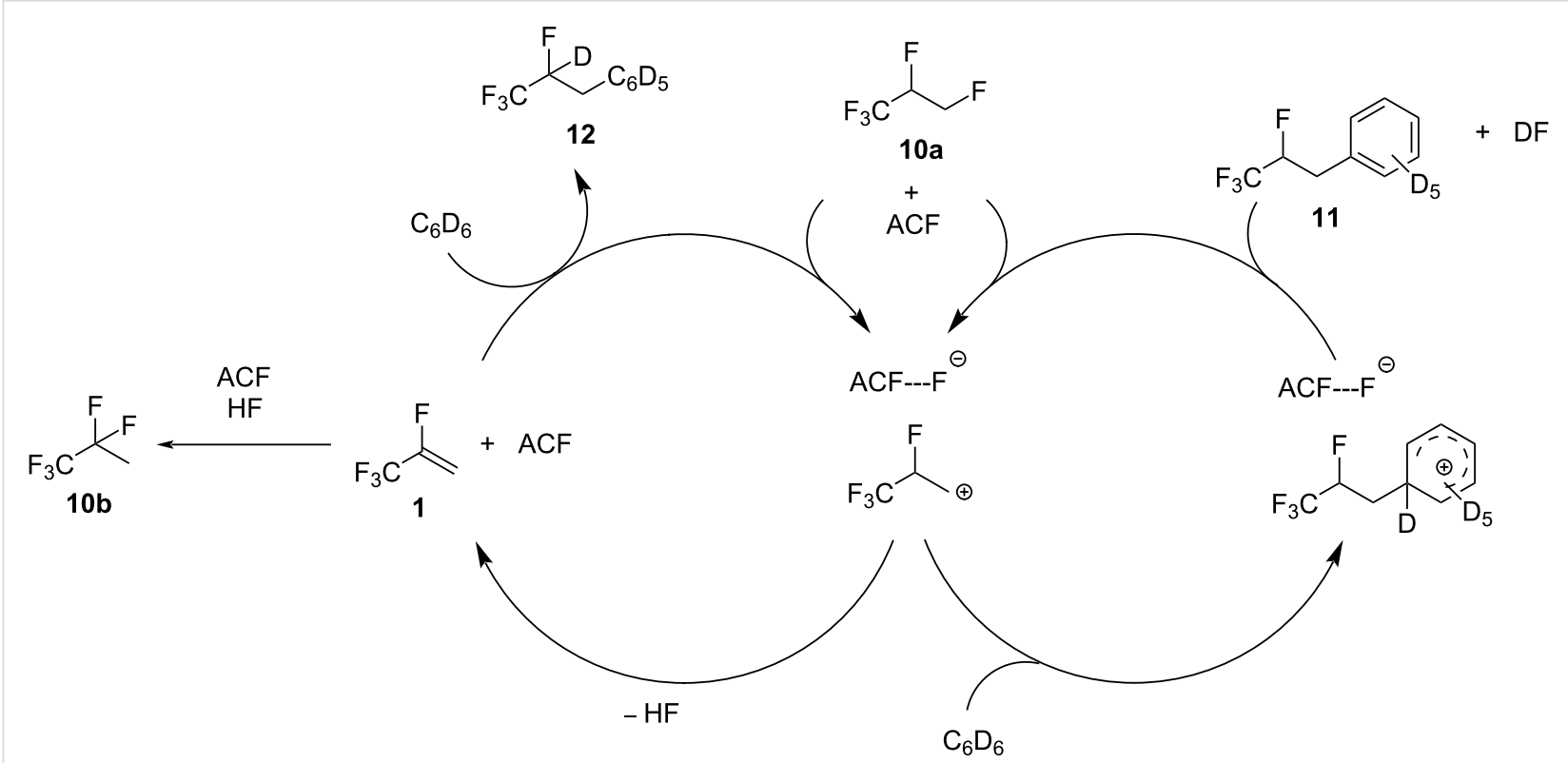

Scheme 3: Proposed catalytic cycle of the transformation of $10 a$ in $C_{6} D_{12}$ and $C_{6} D_{6}$ in the presence of $A C F$ as the catalyst.

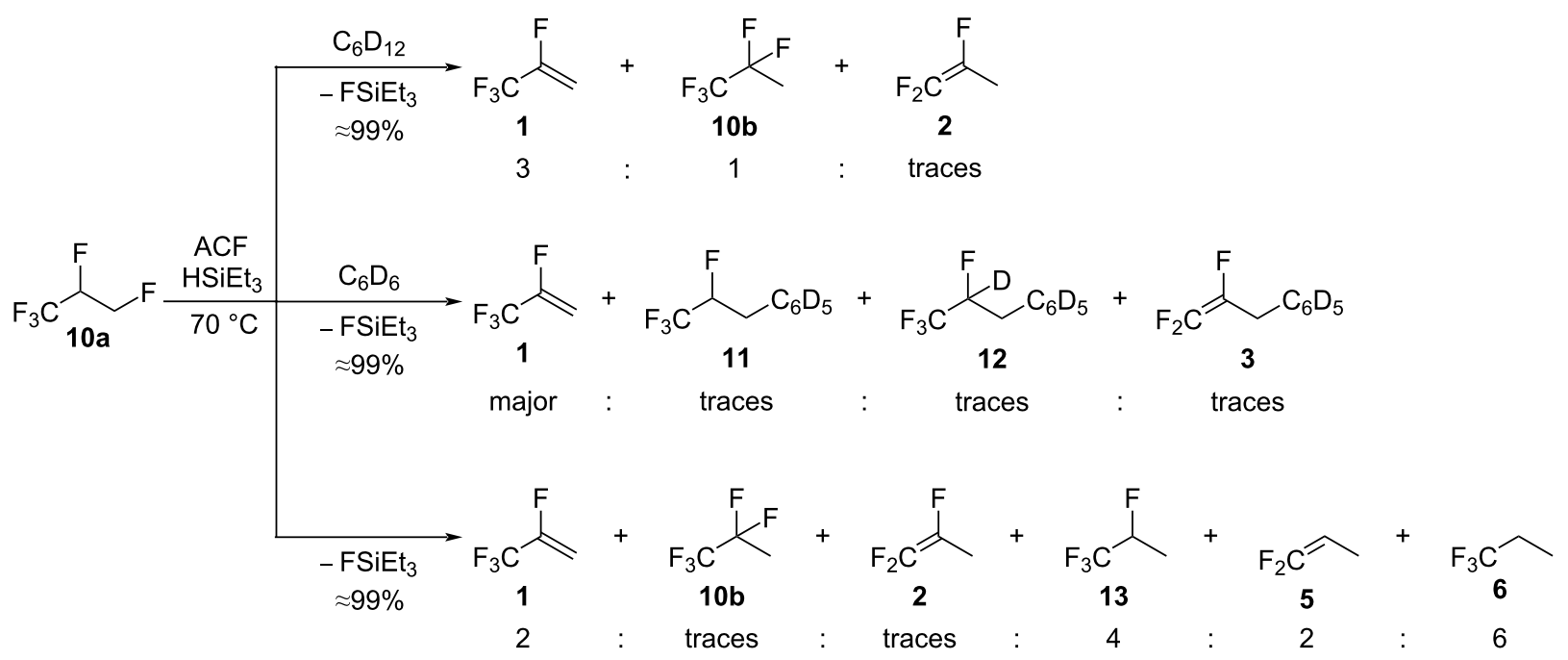

Scheme 4: Reactivity of $10 \mathrm{a}$ in the presence of $\mathrm{ACF}$ as the catalyst and $\mathrm{HSiEt}_{3}$ as a hydrogen source in $\mathrm{C}_{6} \mathrm{D}_{12}$ (top) or $\mathrm{C}_{6} \mathrm{D}_{6}$ (middle) as solvents or in neat silane (bottom).

middle). Compound 10a is transformed into $\mathbf{1}, \mathbf{1 1}$, and $\mathbf{1 2}$ with the additional presence of traces of the Friedel-Crafts product $\mathrm{CF}_{2}=\mathrm{CFCH}_{2} \mathrm{C}_{6} \mathrm{D}_{5}$ (3). However, in neat silane, 10a was converted into 1, 10b, 2, 1,1,1,2-tetrafluoropropane (13), 1,1-difluoropropene (5), and 1,1,1-trifluoropropane (6, Scheme 4, bottom). Thus, by having a large excess of silane, a consecutive reactivity was observed, which led to the formation of the hydrodefluorination product $\mathbf{6}$ as the main compound. However, the reaction is unselective, and various intermediates are still present in considerable amounts (Scheme 4).
Note, that for the transformation in the presence of silane, the conversions reached over $99 \%$ after 7 days at $70{ }^{\circ} \mathrm{C}$, which underlines the significant role of the silane in the reaction mixture. The improved conversion can generally arise from an interaction of silane with the surface of $\mathrm{ACF}$, also competing with the above-mentioned benzene interaction. Furthermore, in the presence of silane, additional mechanistic $\mathrm{C}-\mathrm{F}$ activation steps have to be considered (Scheme 5). Basically, the immobilization of silane at the Lewis-acidic surface might result in silylium-like species, which subsequently initiate the $\mathrm{C}-\mathrm{F}$ bond 


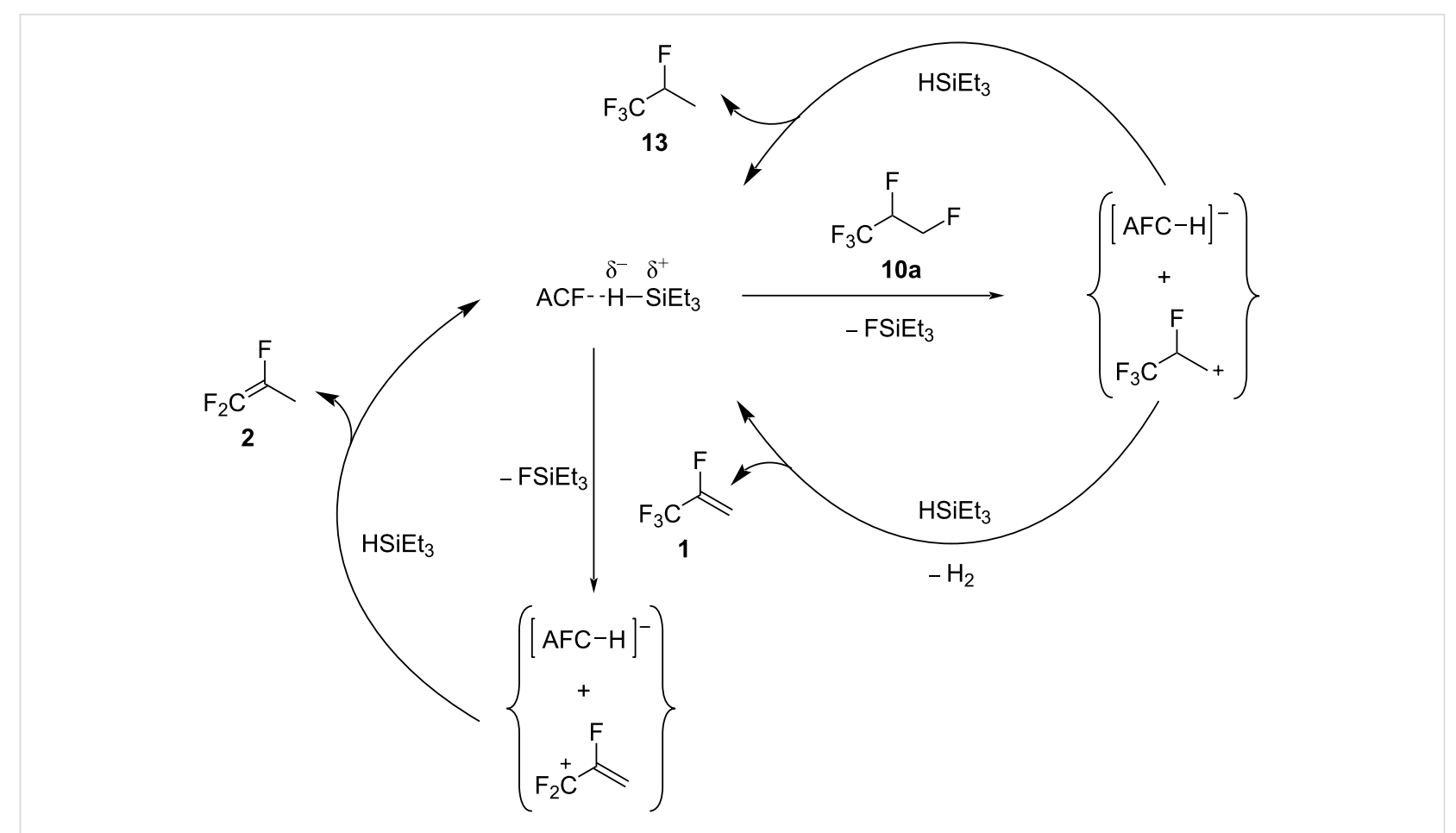

Scheme 5: Proposed catalytic cycle for sylilium-mediated hydrodefluorinations and dehydrofluorinations from 10a at the surface of ACF.

activation at the primary carbon-fluorine bond in $\mathbf{1 0 a}$, generating $\mathrm{FSiEt}_{3}$, the corresponding carbenium-like species, and a surface-bound hydride. At this stage, either the hydrodefluorination product $\mathbf{1 3}$ can be generated, or dehydrofluorination occurs to furnish the olefin 1 and $\mathrm{H}_{2}$, both in the presence of silane. Additionally, $\mathbf{1}$ can further react with any silylium ion species at the surface of $\mathrm{ACF}$, resulting in a $\mathrm{C}-\mathrm{F}$ bond cleavage at the $\mathrm{CF}_{3}$ group, yielding once again a surface hydride and the corresponding carbenium ion. Subsequently, the allylic hydrodefluorination product $\mathbf{2}$ is formed. Allylic hydrodefluorination reactions were previously observed at ACF. Indeed, in the presence of silane and $\mathrm{ACF}$, the $\mathrm{CF}_{3}$ group in tetrafluoropropenes (HFO-1234yf, 1 and HFO-1234ze, 4) was transformed into an olefinic $\mathrm{CF}_{2}$ group (Scheme 1) [16]. Previous MAS NMR studies also gave evidence for the existence of silylium species at an ACF surface [39,47]. In addition, silylium species that are stabilized by weakly coordinating anions can also catalyze hydrodefluorination reactions in a homogeneous phase with silanes as hydrogen source [54-57]. In contrast, silylium-mediated dehydrofluorination reactions have not been found in a homogeneous phase, but germylium ions can promote such reaction pathways [58]. Nevertheless, the formation of the compounds $\mathbf{1}, \mathbf{1 0 b}, \mathbf{1 1}$, and $\mathbf{1 2}$ can alternatively be initiated by the Lewis acidity of ACF itself, as outlined above without the presence of silane (see Scheme 3). Therefore, as an alternative to the initial formation of the surface silylium ion species at ACF, it is in principle also conceivable that car- benium species can be initially produced by an abstraction of a fluoride ion from a fluorinated group by the surface of the catalyst. Then, carbenium ions can react with silane to yield hydrodefluorination products, or after dehydrofluorination, $\mathrm{HF}$ that in the presence of silane, produces $\mathrm{FSiEt}_{3}$ and $\mathrm{H}_{2}[39,50]$. Furthermore, any intermediate carbenium species, generated directly at the ACF surface or via interaction with a silylium species, can be engaged in Friedel-Crafts-like reactions to give with $\mathrm{C}_{6} \mathrm{D}_{6} \mathbf{1 1}$ or $\mathbf{3}$, which is consistent with previous studies [16].

The formation of the products described above (Scheme 4) involves consecutive reaction steps, such as dehydrofluorination, hydrodefluorination, hydrofluorination, allylic defluorination, hydroarylation, and Friedel-Crafts reactions. In the presence of an excess of silane, the dehydrofluorination product 1 and the hydrodefluorination intermediate $\mathbf{1 3}$ are generated simultaneously to further lead to $\mathbf{2 ,} \mathbf{5}$, and $\mathbf{6}$ as the main compounds. To get further insight, independent reactions were performed to elucidate reaction patterns and to demonstrate the conceivable transformations between certain products, which were observed in the activation of 10a in the presence of ACF and $\mathrm{HSiEt}_{3}$.

It turned out that the tetrafluoropropene $\mathbf{1 3}$ reacts in the presence of silane with ACF as the catalyst in $\mathrm{C}_{6} \mathrm{D}_{12}$ or neat silane to give 5 and $\mathbf{6}$ (ratio 1:2, Scheme 6 , top). When $\mathrm{C}_{6} \mathrm{D}_{6}$ was used 


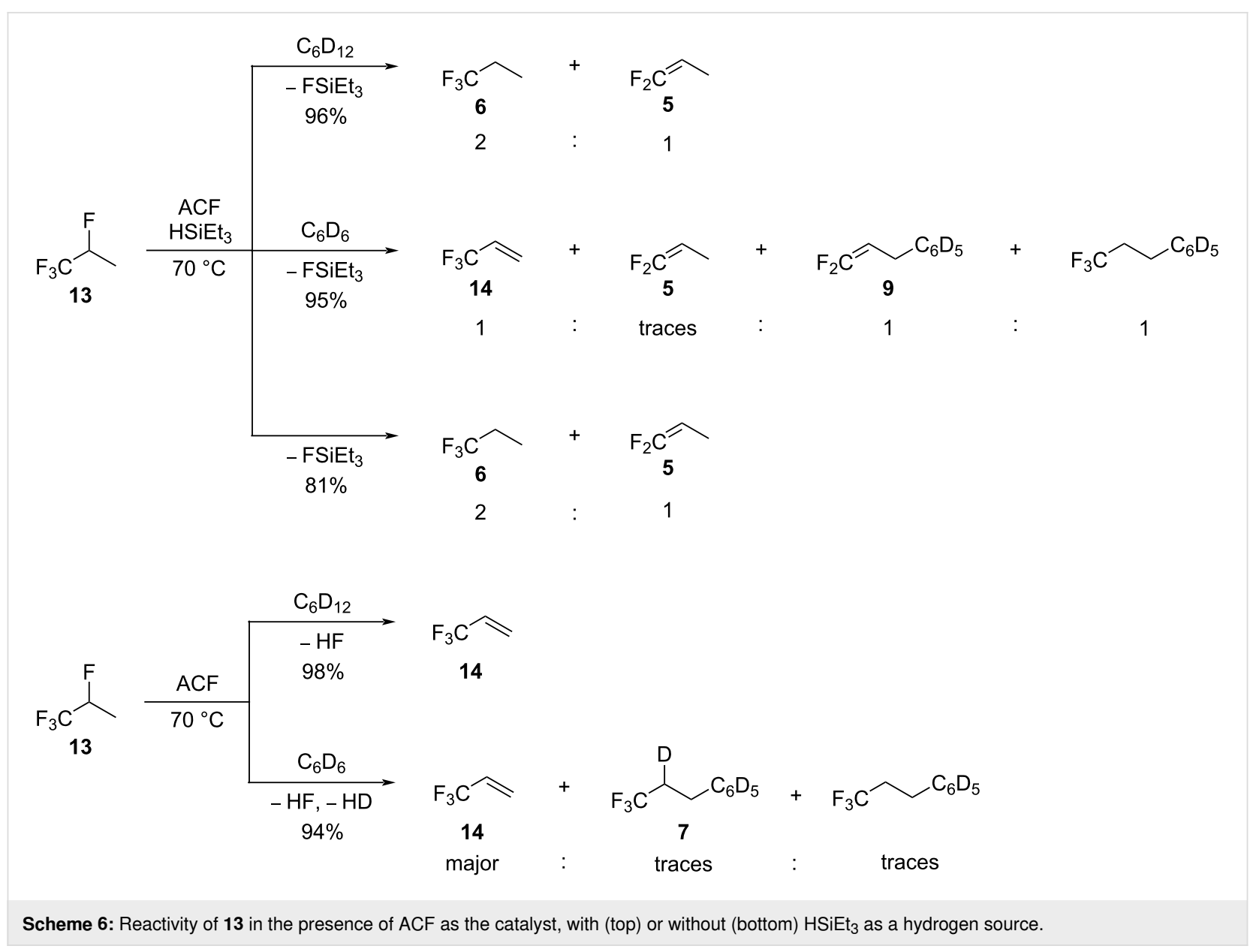

as a solvent in the presence of silane, 5, 14, 9, and the Friedel-Crafts product $\mathrm{CF}_{3} \mathrm{CH}_{2} \mathrm{CH}_{2} \mathrm{C}_{6} \mathrm{D}_{5}$ were generated. Note, that in this context, in the absence of silane and in $\mathrm{C}_{6} \mathrm{D}_{12}$, the selective formation of $\mathbf{1 4}$ was detected (Scheme 6, bottom). In benzene, $\mathbf{1 4}$ was also formed as the main compound, together with the corresponding Friedel-Crafts and hydroarylation products, both observed in traces. This suggests that silane promotes the generation of $\mathbf{5}$ and $\mathbf{6}$, but for the formation of $\mathbf{1 4}$ it is not essential.

Furthermore, another independent reaction by treating 5 with HF was performed (Scheme 7, top), but the hydrofluorination product 6 was only detected in small amounts. In accordance with this result, the treatment of $\mathbf{6}$ in the presence of silane and ACF gave the dehydrofluorination product 5 . The observations nevertheless suggest the presence of an equilibrium between $\mathbf{5}$ and $\mathbf{6}$, that depends on the amount of $\mathrm{HF}$ or $\mathrm{HSiEt}_{3}$ present in the reaction mixture.

Additionally, it is conceivable that $\mathbf{1 4}$ can further react to form 5 via allylic hydrodefluorination [16]. Therefore, the reactivity of $\mathbf{1 4}$ was tested in the presence of $\mathrm{ACF}$ and silane in $\mathrm{C}_{6} \mathrm{D}_{12}$ or
$\mathrm{C}_{6} \mathrm{D}_{6}$ (Scheme 7, bottom). Indeed, in $\mathrm{C}_{6} \mathrm{D}_{12}$, allylic defluorination to yield 5 was observed, together with 6 and traces of 2-chloro-1,1,1-trifluoropropene (15). The chlorinated product 15 could stem from a plausible $\mathrm{HCl}$ formation if the substrate is fluorinating ACF [41]. It should be noted that the synthesis of ACF itself consists of the fluorination of $\mathrm{AlCl}_{3}$ by chlorofluoroalkanes [40,41]. Nevertheless, in $\mathrm{C}_{6} \mathrm{D}_{6}$, the formation of 5 and 6 and the Friedel-Crafts product $\mathrm{CF}_{2}=\mathrm{CHCH}_{2} \mathrm{C}_{6} \mathrm{D}_{5}(\mathbf{9})$ was observed from 14.

Based on these findings, a general scheme can be drafted to illustrate the sequential generation of products starting from 10a for the conversions in the presence of silane at ACF (Scheme 8). Note, that the reaction of $\mathbf{1}$ in the presence of silane, ACF, and solvents was repeated under the same conditions as for the activation of 10a, and the generation of $\mathbf{2}$ and $\mathbf{3}$ was confirmed similarly as reported (see above, Scheme 1) [16].

Overall, the reactivity study on $\mathbf{1 0 a}$ in the presence of ACF and $\mathrm{HSiEt}_{3}$ suggests that the formation of $\mathbf{1}$ described in the top part of the mechanism is favored when no silane is present in the 

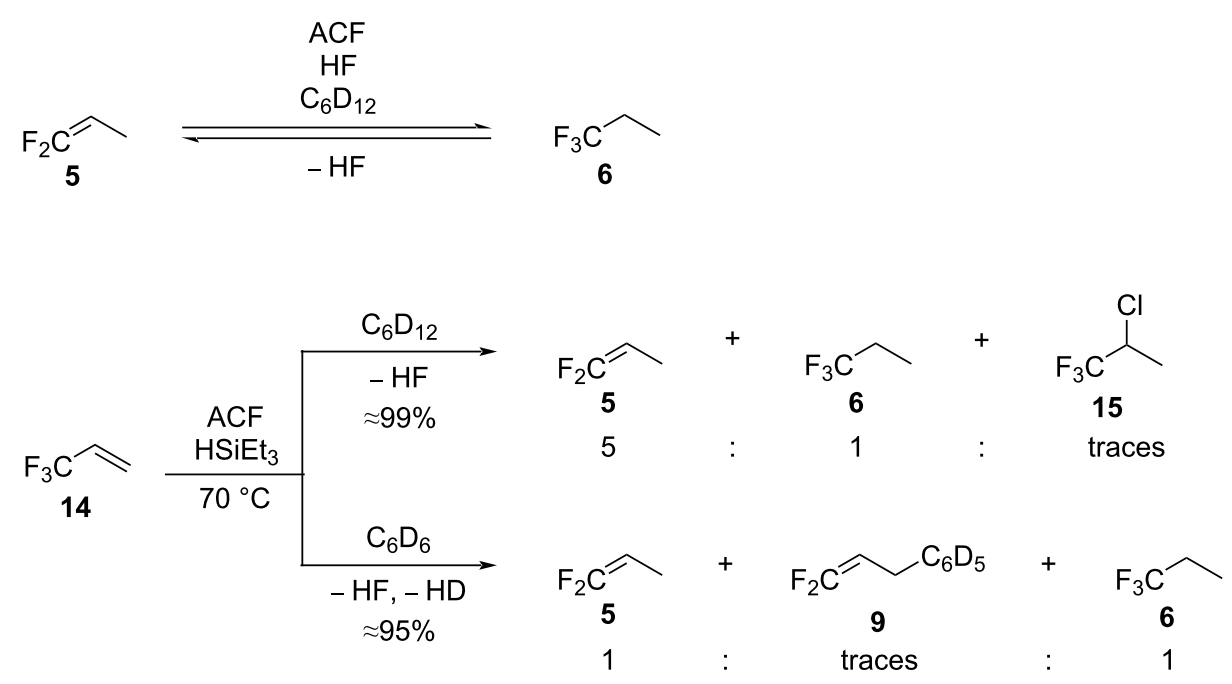

Scheme 7: Independent reactions starting from 5, 6, or 14 in the presence of ACF as the catalyst.<smiles>O=S(=O)(O)CC(F)C(F)(F)F</smiles>

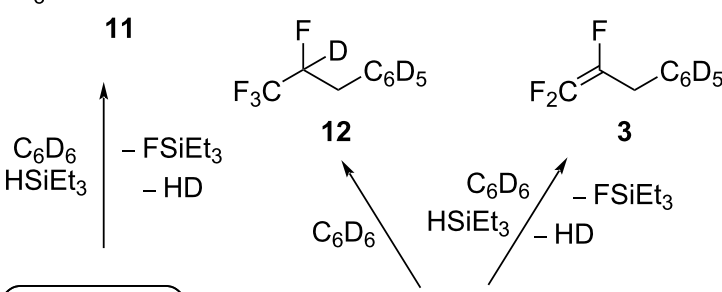

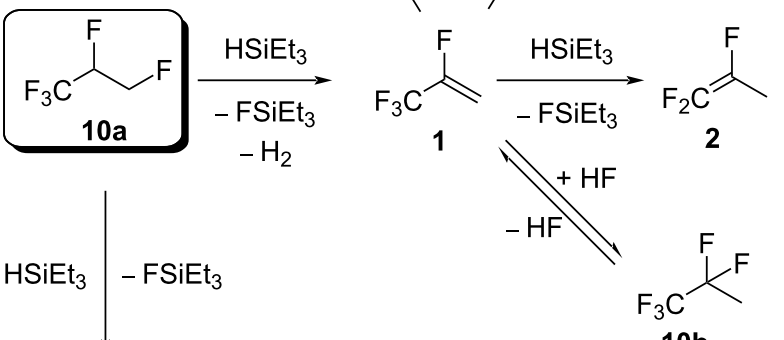
$10 \mathrm{~b}$

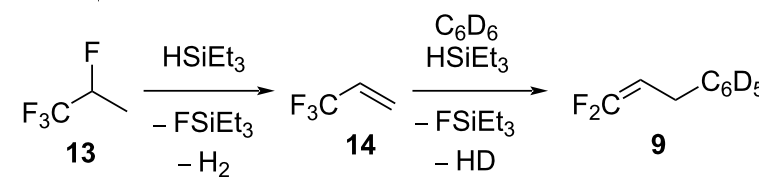<smiles>CCCCCCCCCCCCCCCC</smiles>

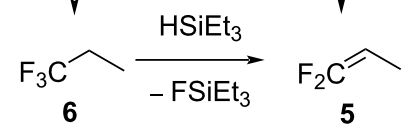

Scheme 8: Proposed reaction pathways starting from $10 \mathrm{a}$ in the presence of ACF and silane. reaction mixture or when only a small amount of silane is present (Scheme 8). In contrast, in neat silane, the bottom part of Scheme 8 is preferred, leading to the formation of 6 .

\section{Activation of 1,1,1,3,3-pentafluoropropane (HFC-245fa, 10c)}

The reactivity of 1,1,1,3,3-pentafluoropropane (10c) at ACF was compared with the one of the isomer 1,1,1,2,3-pentafluoropropane (10a), again to elucidate conceivable reaction pathways and to understand potential similarities in their reactivity. In contrast to the findings for $\mathbf{1 0 a}$, no conversion was observed without the use of $\mathrm{HSiEt}_{3}$ as a hydrogen source, indicating that for the activation of $\mathrm{CHF}_{2}$ groups, silane might be required.

When 10c was treated with 0.5 equivalents of $\mathrm{HSiEt}_{3}$ with respect to the substrate in the presence of ACF at $70{ }^{\circ} \mathrm{C}$, the selective generation of the 1,3,3,3-tetrafluoropropenes (HFO$1234 z e, 4 a$ and $4 b$ ) was detected with an $E: Z$ ratio of 10:1 and $43 \%$ conversion (Scheme 9). The transformation of $10 \mathbf{c}$ into $4 \mathbf{a}$ and $\mathbf{4 b}$ is remarkable since other catalytic conversions at chromia-based catalysts require elevated temperatures [11,19,59-62].

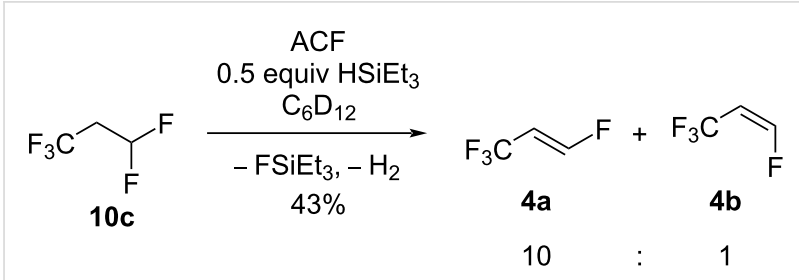

Scheme 9: Reactivity of $10 \mathrm{c}$ in the presence of ACF as the catalyst and 0.5 equivalents of $\mathrm{HSiEt}_{3}$ as a hydrogen source in $\mathrm{C}_{6} \mathrm{D}_{12}$. 
The mechanisms for the $\mathrm{C}-\mathrm{F}$ bond cleavage starting from 10c to yield the isomers $\mathbf{4}$ are similar to the ones proposed in the activation of 10a in the presence of silane (see above, Scheme 5). It is likely that silylium species are involved in the $\mathrm{C}-\mathrm{F}$ activation steps at the ACF surface since $\mathrm{HSiEt}_{3}$ is needed to initiate any reactivity. On the one hand, an initial $\mathrm{C}-\mathrm{F}$ bond activation at $10 \mathrm{c}$ by some silylium ion species will produce $\mathrm{FSiEt}_{3}$ and the corresponding carbenium species (Scheme 10). The latter can generate $4 \mathbf{a}$ and $4 \mathbf{b}$ together with $\mathrm{H}_{2}$, leading to the regeneration of the catalyst. When only 0.5 equivalents of silane are present, the reaction does not pursue further, as shown above (Scheme 9). On the other hand, as for 10a, an alternative mechanism can be proposed where the carbenium species is initially generated by an abstraction of a fluoride ion at the $\mathrm{CHF}_{2}$ group by the surface of the catalyst. Via HF elimination, $\mathbf{4 a}$ and $\mathbf{4 b}$ are produced, and the conversion is driven by the $\mathrm{HF}$ reaction with $\mathrm{HSiEt}_{3}$ to give $\mathrm{FSiEt}_{3}$.

When the amount of silane was increased to one equivalent, further reactivity was observed (Scheme 11). In $\mathrm{C}_{6} \mathrm{D}_{12}, 6$ was generated as the main compound, with traces of $\mathbf{5}$ and $\mathbf{1 4}$ (Scheme 11, top). When $\mathrm{C}_{6} \mathrm{D}_{6}$ was used as the solvent, $\mathbf{5}$ as the main product, $\mathbf{6}$ as a minor product, and $\mathbf{1 4}$ in traces were again generated, together with the Friedel-Crafts products $\mathrm{CF}_{2}=\mathrm{CHCH}_{2} \mathrm{C}_{6} \mathrm{D}_{5}(\mathbf{9})$ and $\mathrm{CF}_{3} \mathrm{CH}=\mathrm{CHC}_{6} \mathrm{D}_{5}(\mathbf{8}$, Scheme 11 , middle). In neat silane, $\mathbf{5}$ and $\mathbf{6}$ were detected in a ratio of $1: 4$ (Scheme 11, bottom)

Notably, for all conversions $\left(\mathrm{C}_{6} \mathrm{D}_{6}\right.$ and silane, $\mathrm{C}_{6} \mathrm{D}_{12}$ and silane, or in neat silane), monitoring of the reaction by

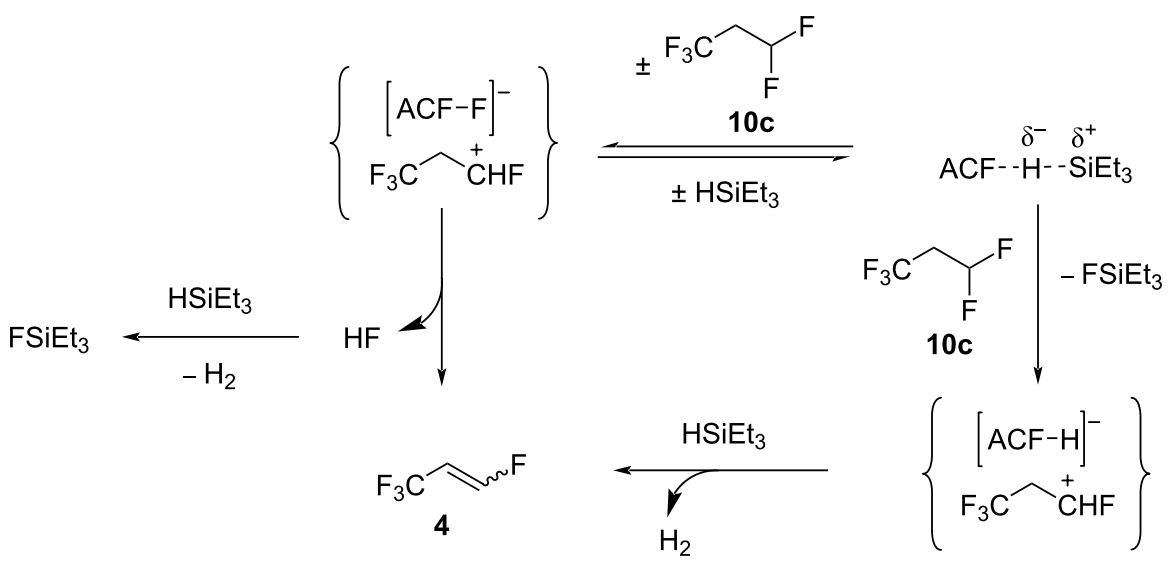

Scheme 10: Proposed catalytic cycles for the transformation of $10 \mathrm{c}$ in $\mathrm{C}_{6} \mathrm{D}_{12}$ and in the presence of 0.5 equivalents of silane and ACF as the catalyst.

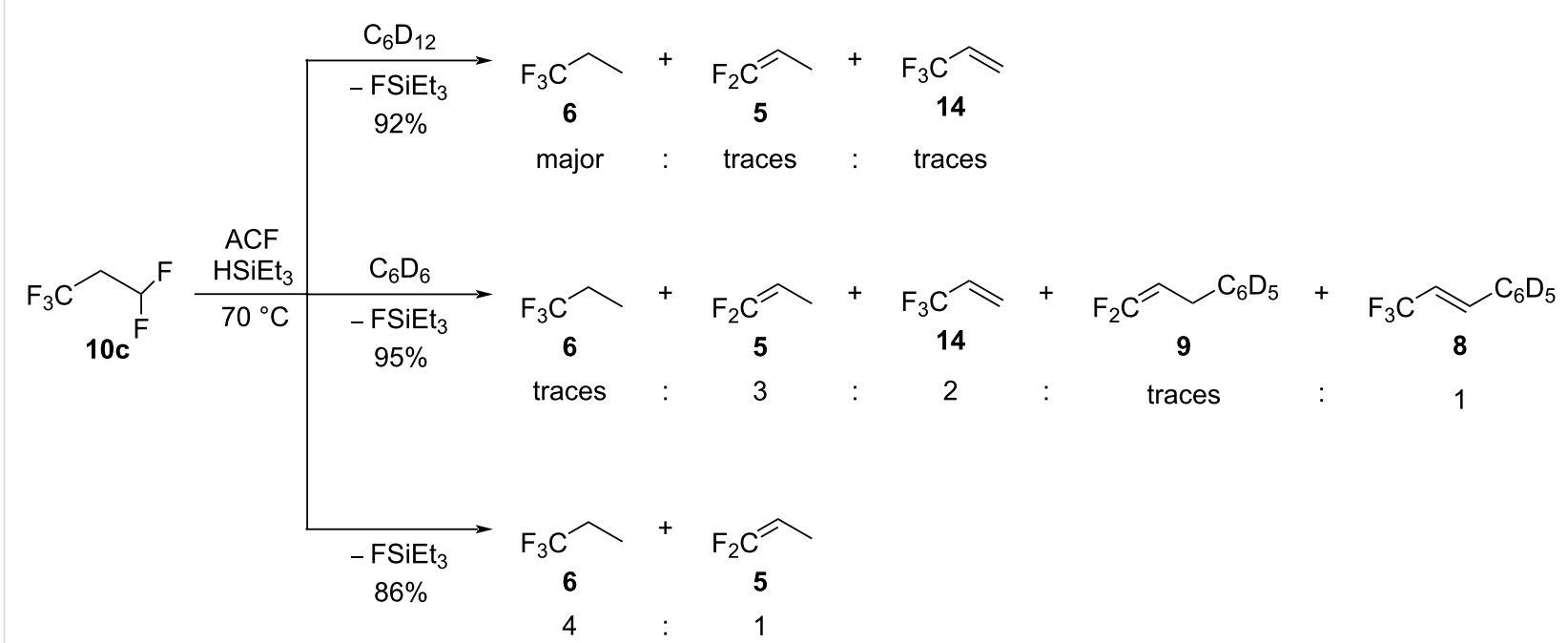

Scheme 11: Reactivity of $10 \mathrm{c}$ in the presence of $A C F$ as the catalyst and $\mathrm{HSiEt}_{3}$ as a hydrogen source in $\mathrm{C}_{6} \mathrm{D}_{12}$ (top) or $\mathrm{C}_{6} \mathrm{D}_{6}$ (middle) as solvents or in neat silane (bottom). 
${ }^{19}$ F NMR spectroscopy led to the observation of the early generation of $\mathbf{4 a}$ and $\mathbf{4 b}$ after 24 hours reaction time at $70{ }^{\circ} \mathrm{C}$. After 3 days at $70{ }^{\circ} \mathrm{C}$, the transformation into the different products described above could be detected. Moreover, the continuous formation of $\mathrm{FSiEt}_{3}$ over time was observed for all reactions, which underlines the crucial role of the hydrogen source at each reaction step. As stated, it has been reported before that for the activation of 1,3,3,3-tetrafluoropropene (HFO-1234ze, 4) at $\mathrm{ACF}$ in neat $\mathrm{HSiEt}_{3}$ 1,1-difluoropropene (5) and 1,1,1-trifluoropropane (6) are furnished (Scheme 1) [16]. In the presence of $\mathrm{C}_{6} \mathrm{D}_{6}$ and silane, the Friedel-Crafts products $\mathrm{CF}_{2}=\mathrm{CHCH}_{2} \mathrm{C}_{6} \mathrm{D}_{5}$ (9) and $\mathrm{CF}_{3} \mathrm{CH}=\mathrm{CHC}_{6} \mathrm{D}_{5}(\mathbf{8})$ were observed, together with the hydroarylation product $\mathrm{CF}_{3} \mathrm{CHDCH}_{2} \mathrm{C}_{6} \mathrm{D}_{5}$ (7) [16]. To note, in neat silane, a distinct selectivity was detected, depending on the substrates used. Indeed, starting from $10 \mathrm{c}$, the product ratio between 5 and $\mathbf{6}$ was 1:4, whereas it was reported to be 1:0.8 starting from $4 \mathbf{a}$ [16]. This observation might be the result of a hydrofluorination reaction from $\mathbf{5}$ to $\mathbf{6}$. Moreover, in neat silane, $\mathbf{1 4}$ was not detected, whereas when less silane and a solvent was present, this product was observed. Due to a large amount of silane present, a more considerable amount of the silylium species can be generated compared to when only one equivalent of silane is used. Therefore, the rate of the reaction from 10c to 6 might be increased in neat silane favoring two subsequent hydrodefluorination steps from $10 \mathrm{c}$ to yield 6.

As observed in the study on the reactivity of 10a, the variety of products for a larger amount of silane can be explained by several consecutive reactions, which include $\mathrm{C}-\mathrm{F}$ bond activation steps (Scheme 12). Via hydrodefluorination, 10c can produce the intermediate 1,1,1,3-tetrafluoropropane (not observed). This intermediate could give 6 via a second hydrodefluorination. Alternatively, 1,1,1,3-tetrafluoropropane could also produce 14, which was shown to give 6 via the intermediate $\mathbf{5}$ by independent reactions. However, pathways to yield $\mathbf{6}$ are also required from the olefins $\mathbf{4}$, because they were detected as intermediates. This implies HF addition to $\mathbf{4}$ or $\mathbf{5}$. In the presence of benzene, $\mathbf{1 4}$ can also generate the Friedel-Crafts product 9; however, product 9 can also be generated from $\mathbf{4}$ by hydrodefluorination followed by a Friedel-Crafts reaction. The Friedel-Crafts product $\mathbf{8}$ can as well be formed from 10c directly, via a Friedel-Crafts reaction followed by HF elimination.

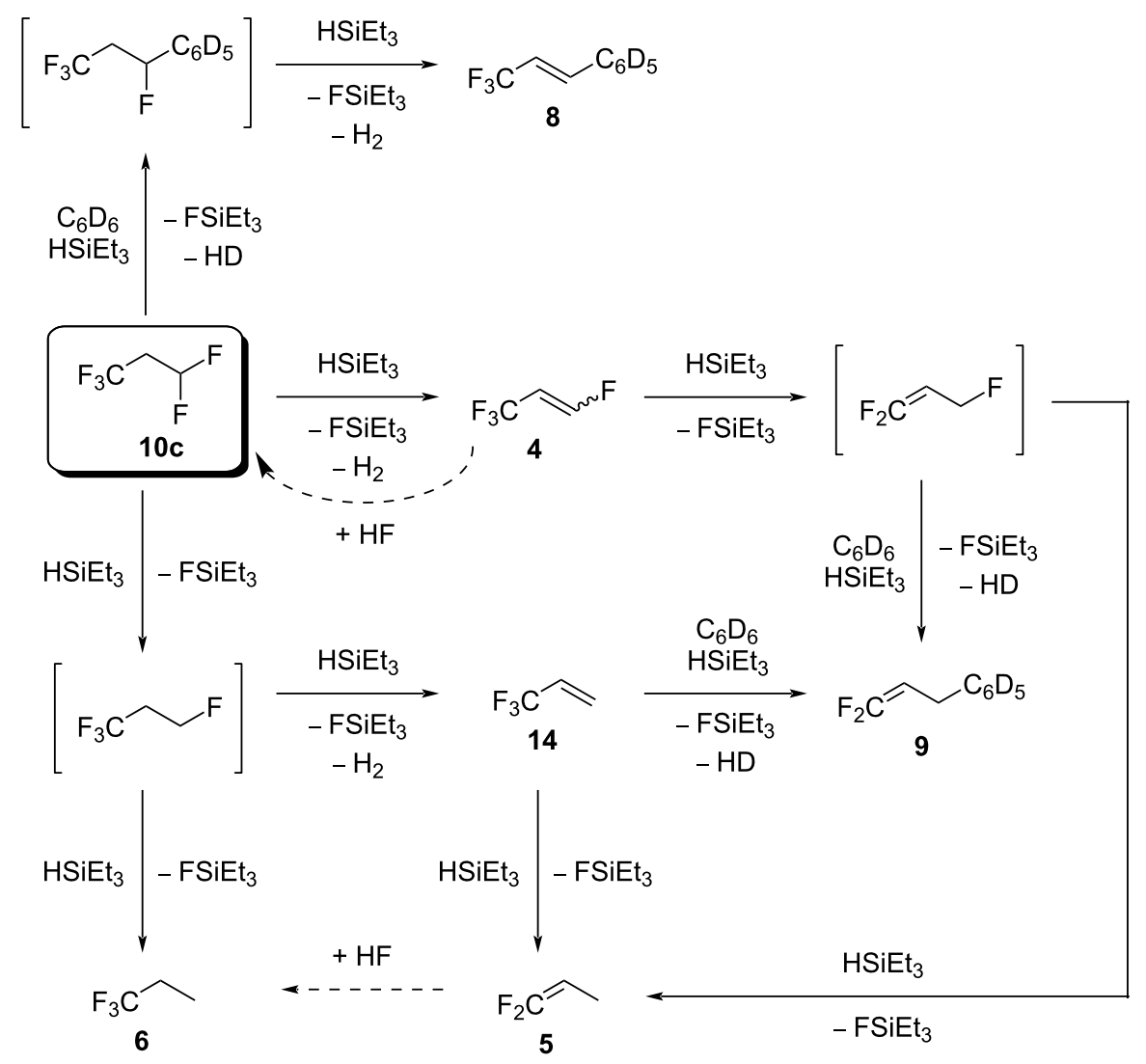


Comparable to the reaction patterns of $\mathbf{1 0 a}$, the reactivity study on 10c reveals that with a small amount of silane, the dehydrofluorination to $\mathbf{4}$ is favored, and with more silane, the conversions in Scheme 12 end up favorably in the formation of $\mathbf{6}$.

\section{Activation of 1,1,1,2,2-pentafluoropropane (HFC-245fa, 10b)}

As observed for 10c, the isomeric 1,1,1,2,2-pentafluoropropane (HFC-245fa, 10b) could also not be activated without the presence of $\mathrm{HSiEt}_{3}$ as a hydrogen source. The treatment of $\mathbf{1 0 b}$ in $\mathrm{C}_{6} \mathrm{D}_{12}$ in the presence of silane at $70{ }^{\circ} \mathrm{C}$ gave the allylic hydrodefluorination product $\mathbf{2}$ as well as $\mathbf{5}$ in a ratio of 1:1 with $38 \%$ conversion (Scheme 13, top). When benzene was used as a solvent together with silane, the Friedel-Crafts products $\mathbf{3}$ and 9 were observed in a ratio of $1: 1$, but the conversion reached only 18\% (Scheme 13, middle). In neat silane, $\mathbf{2}$ and $\mathbf{5}$ were again observed, but this time the conversion did not exceed $10 \%$ (Scheme 13, bottom).

As for the activation of $\mathbf{1 0 c}$, it is plausible that surface silylium ion species are formed at ACF. Therefore, a reaction pathway can be suggested, starting with the initial generation of $\mathbf{1}$, $\mathrm{FSiEt}_{3}$, and $\mathrm{H}_{2}$. Subsequently, 2 can be generated via an allylic hydrodefluorination as it was observed in the study of tetrafluoropropenes at ACF [16]. Additionally, 5 can stem from several $\mathrm{C}-\mathrm{F}$ bond activations at $\mathbf{1 0 b}$, starting with a hydrodefluorination to generate the intermediate $\mathbf{1 3}$, which further undergoes an $\mathrm{HF}$ elimination, followed by an allylic hydrodefluorination to give $\mathbf{5}$. In the presence of benzene, at $\mathbf{1}$, a Friedel-Crafts reaction can generate $\mathbf{3}$, which further supports the formation as an intermediate of $\mathbf{1}$. Moreover, the intermediate $\mathbf{1 4}$ can also produce 9 via a Friedel-Crafts reaction, which again supports the pathway proposed to achieve 5

Overall, for the reactivity of the pentafluoropropane isomer 10b, two different pathways seem to compete. The upper part of the reaction patterns in Scheme 14 leads to the formation of $\mathbf{2}$, and the bottom part provides pathways to $\mathbf{5}$. Thus, the hydrodefluorination step at $\mathbf{1 0 b}$ to form $\mathbf{1 3}$ seems to be more difficult than for the other isomers $\mathbf{1 0 a}$ and 10c.

\section{Conclusion}

This study on the reactivity of pentafluoropropane isomers has revealed that ACF is a suitable catalyst for dehydrofluorination and hydrodefluorination reactions of polyfluorinated compounds under mild conditions. It was elaborated that the single $\mathrm{C}-\mathrm{F}$ bond in $\mathbf{1 0 a}$ does not require the use of $\mathrm{HSiEt}_{3}$ as a hydrogen source to be activated via dehydrofluorination. However, when silane was introduced, further reactivity was observed, leading to the formation of subsequent defluorination products. In contrast, $\mathrm{CF}_{2}, \mathrm{CHF}_{2}$, and $\mathrm{CF}_{3}$ groups need the presence of a hydrogen source in order to promote the activation of at least one $\mathrm{C}-\mathrm{F}$ bond by the formation of the thermodynamically stable $\mathrm{Si}-\mathrm{F}$ bond. This observation is consistent with a decrease of the bond dissociation energies of $\mathrm{C}-\mathrm{F}$ bonds from trifluoromethyl via difluoromethyl to monofluoromethyl groups [63]. Additionally, the $\mathrm{C}-\mathrm{F}$ bond at the $\mathrm{CHF}_{2}$ group in 10c was easier to activate than the $\mathrm{C}-\mathrm{F}$ bond in the $\mathrm{CF}_{3} \mathrm{CF}_{2}$ group in $10 \mathrm{c}$, resulting in an order of reactivity of $\mathbf{1 0 a}>\mathbf{1 0 c}>\mathbf{1 0 b}$. When only a small amount of silane was introduced for the reaction of $10 \mathrm{a}$ or $10 \mathrm{c}$, the major products are due to dehydrofluorination, whereas in neat silane, formally hydrodefluorination products are gener-

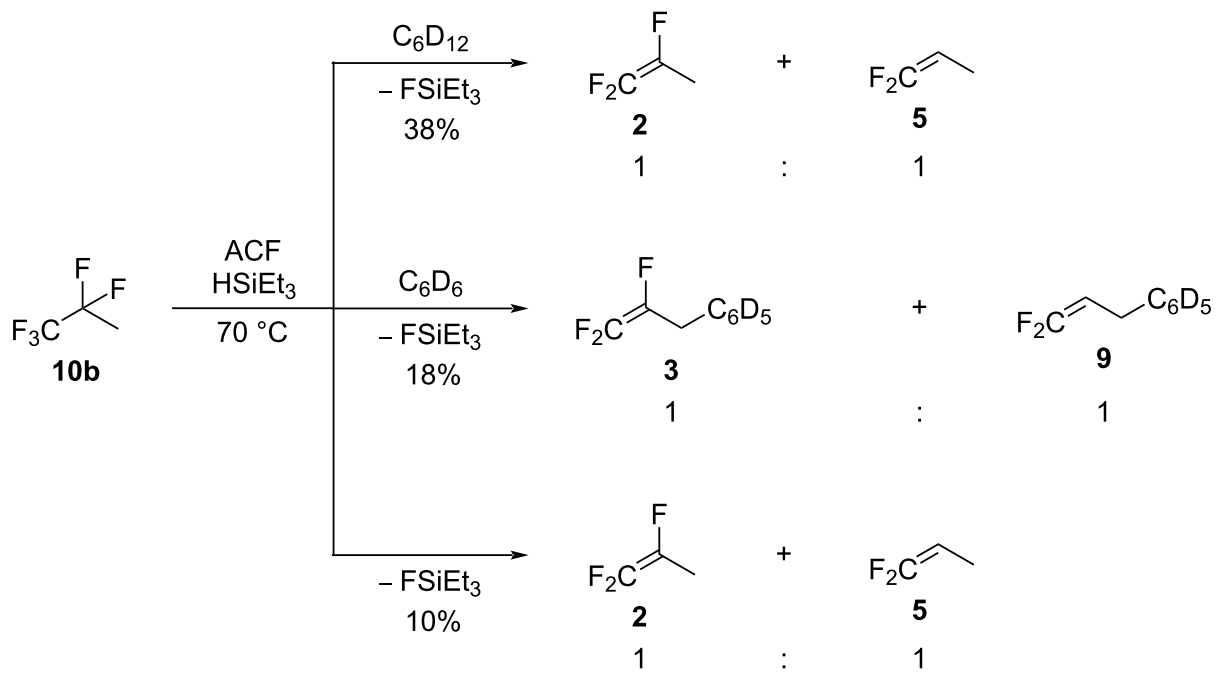

Scheme 13: Reactivity of $10 \mathrm{~b}$ in the presence of ACF as the catalyst and $\mathrm{HSiEt}_{3}$ as a hydrogen source in $\mathrm{C}_{6} \mathrm{D}_{12}$ (top) or $\mathrm{C}_{6} \mathrm{D}_{6}$ (middle) as solvents or in neat silane (bottom). 


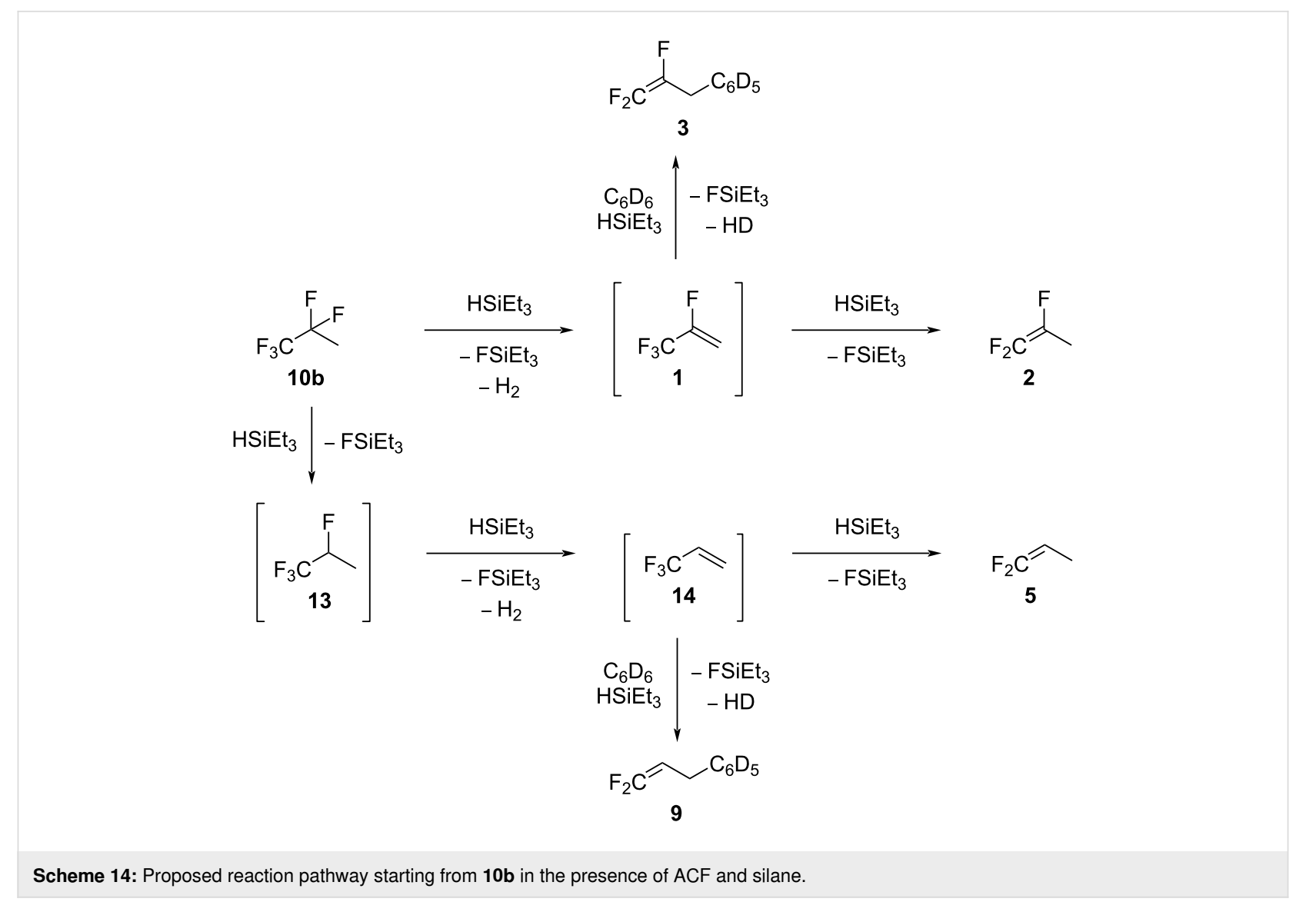

ated mainly. By using $\mathrm{C}_{6} \mathrm{D}_{6}$, various Friedel-Crafts products can be further generated. For $\mathbf{1 0 b}$, the conversions are very low, but dehydrofluorination and hydrodefluorination pathways compete with each other.

Mechanistically, the C-F bonds of the fluorinated substrates can be activated by Lewis-acidic sites at the ACF surface. In the presence of silane, it can be assumed that preferentially silylium surface species initiate the $\mathrm{C}-\mathrm{F}$ bond cleavage. For both, the generated carbenium species show further reactivity to result in dehydrofluorination, hydrodefluorination, or Friedel-Crafts products. Notably, the conversion in neat silane was lower in the case of 10c and $10 \mathbf{b}$, possibly because of a certain blocking of the acidic sites of ACF by silane. Note in that context that there are reports showing that silylium species can interact with more silane to generate larger entities $[56,58,64]$.

\section{Experimental \\ Material and methods}

The reactions were carried out using Schlenk techniques as well as JYoung NMR tubes. The solvents were purchased from Eurisotop. $\mathrm{C}_{6} \mathrm{D}_{12}$ was dried over molecular sieves and purged with argon prior to use. $\mathrm{C}_{6} \mathrm{D}_{6}$ was dried with $\mathrm{K}$-Solvona and distilled prior to use. $\mathrm{Et}_{3} \mathrm{SiH}(99 \%)$ was purchased from
Sigma-Aldrich in a sure seal bottle and stored under argon. 1,1,1,2,3-Pentafluoropropane (HFC-245eb, 10a), 1,1,1,3,3pentafluoropropane (HFC-245fa, 10c), and 1,1,1,2,2-pentafluoropropane (HFC-245cb, 10b) were gifted by Arkema and used without further purification. 3,3,3-Trifluoropropene (14, 99\%), 1,1,1-trifluoropropane (6), and 1,1,1,2-tetrafluoropropane (13) were purchased from abcr and used without further purification. 1,1-Difluoropropene (5) was bought from Apollo Scientific and used without further purification. ACF was synthesized according to the literature and stored in a glove box. The number of active sites ( $1 \mathrm{mmol}$ acidic sites $/ \mathrm{g}$ of catalyst) was determined by temperature programmed desorption of ammonia $\left(\mathrm{NH}_{3}-\right.$ TPD) $[34,65]$. NMR spectra were recorded at room temperature using a Bruker DPX 300 spectrometer. A capillary of trifluorotoluene was employed as an external standard for quantification purposes. The ${ }^{19} \mathrm{~F}$ NMR spectra were referenced to $\mathrm{PhCF}_{3}(\delta=-63.5 \mathrm{ppm})$ and the chemical shifts in ${ }^{1} \mathrm{H} \mathrm{NMR}$ were referenced to residual $\mathrm{C}_{6} \mathrm{D}_{5} \mathrm{H}(\delta=7.16 \mathrm{ppm})$ or $\mathrm{C}_{6} \mathrm{D}_{11} \mathrm{H}$ $(\delta=1.38 \mathrm{ppm})$.

\section{Procedure for reactions with gaseous substrates}

A JYoung NMR tube was loaded with $25 \mathrm{mg}$ of ACF inside a glovebox. In experiments involving a solvent $\left(\mathrm{C}_{6} \mathrm{D}_{6}\right.$ or $\left.\mathrm{C}_{6} \mathrm{D}_{12}\right)$, 
$0.4 \mathrm{~mL}$ of the solvent was added under Schlenk conditions, together with the corresponding amount of $\mathrm{HSiEt}_{3}$. In the reactions without solvent, $0.5 \mathrm{~mL}$ of $\mathrm{HSiEt}_{3}$ was added using Schlenk techniques to the JYoung NMR tube loaded with ACF. The gases were then condensed using a small glass bulb filled with $0.5 \mathrm{~atm}$ of the corresponding gas $(0.1 \mathrm{mmol})$. The reactions were monitored by ${ }^{1} \mathrm{H}$ and ${ }^{19} \mathrm{~F}$ NMR spectroscopy. The tubes were kept at $70{ }^{\circ} \mathrm{C}$ for 7 days. $\mathrm{PhCF}_{3}$ was used as an external standard in a closed capillary to calculate the conversion based on the consumed substrate by the integration of the ${ }^{19}$ F NMR spectra.

\section{Supporting Information}

\section{Supporting Information File 1}

Analytical data and copies of spectra.

[https://www.beilstein-journals.org/bjoc/content/

supplementary/1860-5397-16-213-S1.pdf]

\section{Acknowledgements}

Special thanks to Dr. Clara Patricia Marshall for the fruitful discussion on the topic.

\section{Funding}

Financial support by the CRC 1349 "Fluorine-Specific Interactions" funded by the Deutsche Forschungsgemeinschaft (gefördert durch die Deutsche Forschungsgemeinschaft (DFG)-Projektnummer 387284271-SFB 1349) is gratefully acknowledged.

\section{ORCID ${ }^{\circledR}$ iDs}

Thomas Braun - https://orcid.org/0000-0003-1629-5352

\section{References}

1. Velders, G. J. M.; Andersen, S. O.; Daniel, J. S.; Fahey, D. W.; McFarland, M. Proc. Natl. Acad. Sci. U. S. A. 2007, 104, 4814-4819. doi:10.1073/pnas.0610328104

2. Ko, M.; Shia, R.-L.; Sze, N.-D.; Magid, H.; Bray, R. G. J. Geophys. Res.: Atmos. 1999, 104, 8173-8181. doi:10.1029/1998jd100097

3. Bolaji, B. O.; Huan, Z. Renewable Sustainable Energy Rev. 2013, 18 , 49-54. doi:10.1016/j.rser.2012.10.008

4. United Nations Environment Programme; Handbook for the Montreal Protocol on Substances That Deplete the Ozone Layer; 2018.

5. United Nations Environment Programme; The Montreal Protocol on Substances That Deplete the Ozone Layer; 2000. doi:10.1163/15718069620847781

6. United Nations Environment Programme; Production and Consumption of Ozone Depleting Substances under the Montreal Protocol; Nairobi, 2005.
7. United Nations Environment Programme; Amendment to the Montreal Protocol on Substances That Deplete the Ozone Layer; 2016.

8. United Nations Environment Programme; Ratification of the Kigali Amendment; 2017.

9. United Nations Environment Programme; The Kigali Amendment to the Montreal Protocol: HFC Phase-Down; 2016.

10. Velders, G. J. M.; Ravishankara, A. R.; Miller, M. K.; Molina, M. J.; Alcamo, J.; Daniel, J. S.; Fahey, D. W.; Montzka, S. A.; Reimann, S. Science 2012, 335, 922-923. doi:10.1126/science.1216414

11. Wang, H.; Tung, H. S. Process for the Production of HFO Trans-1234ze from HFC-245fa. U.S. Patent US8,067,650 B2, July 10, 2011.

12. Light, B. A.; Phillips, S. D.; Fleming, K. M.; Ferguson, S. A.; Ma, J. J.; Bortz, C. L.; Van Der Puy, M.; Merkel, D. C.; Tung, H. S.; Mukhopadhyay, S. Method for Producing Fluorinated Organic Compounds. U.S. Patent US9102579 B2, Jan 3, 2007.

13. Righetti, G.; Zilio, C.; Longo, G. A. Int. J. Refrig. 2015, 54, 1-9. doi:10.1016/j.jirefrig.2015.02.010

14. Fang, X.-X.; Wang, Y.; Jia, W.-Z.; Song, J.-D.; Wang, Y.-J.; Luo, M.-F.; Lu, J.-Q. Appl. Catal., A 2019, 576, 39-46. doi:10.1016/j.apcata.2019.02.035

15. Van Der Puy, M. Process for the Preparation of 2,3,3,3-Tetrafluoropropene (HFO-1234yf). U.S. Patent US8,071,826 B2, Dec 6, 2011.

16. Meißner, G.; Kretschmar, K.; Braun, T.; Kemnitz, E. Angew. Chem., Int. Ed. 2017, 56, 16338-16341. doi:10.1002/anie.201707759

17. Lim, S.; Kim, M. S.; Choi, J.-W.; Kim, H.; Ahn, B. S.; Lee, S. D.; Lee, H.; Kim, C. S.; Suh, D. J.; Ha, J.-M.; Song, K. H. Catal. Today 2017, 293-294, 42-48. doi:10.1016/j.cattod.2016.11.017

18. Wang, F.; Zhang, W.; Liang, Y.; Wang, Y.; Lu, J.; Luo, M. Chem. Res. Chin. Univ. 2015, 31, 1003-1006. doi:10.1007/s40242-015-5190-3

19. Mao, W.; Bai, Y.; Jia, Z.; Yang, Z.; Hao, Z.; Lu, J. Appl. Catal., A 2018, 564, 147-156. doi:10.1016/j.apcata.2018.07.028

20. Shen, Q.; Huang, Y.-G.; Liu, C.; Xiao, J.-C.; Chen, Q.-Y.; Guo, Y. J. Fluorine Chem. 2015, 179, 14-22. doi:10.1016/j.jfluchem.2015.07.007

21. Müller, K.; Faeh, C.; Diederich, F. Science 2007, 317, 1881-1886. doi:10.1126/science.1131943

22. Ni, C.; Hu, J. Chem. Soc. Rev. 2016, 45, 5441-5454. doi:10.1039/c6cs00351f

23. Gilles, P. W.; Margrave, J. L. J. Chem. Phys. 1953, 21, 381-382. doi:10.1063/1.1698915

24. Mazurek, U.; Schwarz, H. Chem. Commun. 2003, 1321-1326. doi:10.1039/b211850e

25. Braun, T.; Wehmeier, F. Eur. J. Inorg. Chem. 2011, 613-625. doi:10.1002/ejic.201001184

26. Amii, H.; Uneyama, K. Chem. Rev. 2009, 109, 2119-2183. doi: $10.1021 / \mathrm{cr} 800388 \mathrm{c}$

27. O'Hagan, D. Chem. Soc. Rev. 2008, 37, 308-319. doi:10.1039/b711844a

28. Krahl, T.; Kemnitz, E. Catal. Sci. Technol. 2017, 7, 773-796. doi:10.1039/c6cy02369j

29. Stahl, T.; Klare, H. F. T.; Oestreich, M. ACS Catal. 2013, 3, 1578-1587. doi:10.1021/cs4003244

30. Fuchibe, K.; Hatta, H.; Oh, K.; Oki, R.; Ichikawa, J. Angew. Chem., Int. Ed. 2017, 56, 5890-5893. doi:10.1002/anie.201701985 
31. Yagupolskii, Yu. L.; Pavlenko, N. V.; Shelyazhenko, S. V.; Filatov, A. A.; Kremlev, M. M.; Mushta, A. I.; Gerus, I. I.; Peng, S.; Petrov, V. A.; Nappa, M. J. Fluorine Chem. 2015, 179, 134-141. doi:10.1016/j.jfluchem.2015.08.001

32. Teinz, K.; Wuttke, S.; Börno, F.; Eicher, J.; Kemnitz, E. J. Catal. 2011, 282, 175-182. doi:10.1016/j.jcat.2011.06.013

33. Teinz, K.; Manuel, S. R.; Chen, B. B.; Pigamo, A.; Doucet, N.; Kemnitz, E. Appl. Catal., B 2015, 165, 200-208. doi:10.1016/j.apcatb.2014.09.076

34. Prechtl, M. H. G.; Teltewskoi, M.; Dimitrov, A.; Kemnitz, E.; Braun, T. Chem. - Eur. J. 2011, 17, 14385-14388. doi:10.1002/chem.201102853

35. Calvo, B.; Braun, T.; Kemnitz, E. ChemCatChem 2018, 10, 403-406. doi:10.1002/cctc.201701327

36. Calvo, B.; Wuttke, J.; Braun, T.; Kemnitz, E. ChemCatChem 2016, 8 , 1945-1950. doi:10.1002/cctc.201600257

37. Siwek, A. K.; Ahrens, M.; Feist, M.; Braun, T.; Kemnitz, E. ChemCatChem 2017, 9, 839-845. doi:10.1002/cctc.201601238

38. Meißner, G.; Feist, M.; Braun, T.; Kemnitz, E. J. Organomet. Chem. 2017, 847, 234-241. doi:10.1016/j.jorganchem.2017.04.030

39. Meißner, G.; Dirican, D.; Jäger, C.; Braun, T.; Kemnitz, E. Catal. Sci. Technol. 2017, 7, 3348-3354. doi:10.1039/c7cy00845g

40. Krahl, T.; Kemnitz, E. J. Fluorine Chem. 2006, 127, 663-678. doi:10.1016/j.jluchem.2006.02.015

41. Krahl, T.; Stösser, R.; Kemnitz, E.; Scholz, G.; Feist, M.; Silly, G.; Buzaré, J.-Y. Inorg. Chem. 2003, 42, 6474-6483. doi:10.1021/ic034106h

42. Krespan, C. G. Process for Production of Polyfluoroolefins. U.S. Pat. Appl. US 5,162,594 A, Nov 11, 1992.

43. Calvo, B.; Marshall, C. P.; Krahl, T.; Kröhnert, J.; Trunschke, A.; Scholz, G.; Braun, T.; Kemnitz, E. Dalton Trans. 2018, 47, 16461-16473. doi:10.1039/c8dt03279c

44. Petrov, V. A.; Krespan, C. G.; Smart, B. E. J. Fluorine Chem. 1998, 89, 125-130. doi:10.1016/s0022-1139(98)00098-0

45. Petrov, V. A.; Krespan, C. G.; Smart, B. E. J. Fluorine Chem. 1996, 77, 139-142. doi:10.1016/0022-1139(96)03391-x

46. Petrov, V. A.; Krespan, C. G. J. Fluorine Chem. 2000, 102, 199-204. doi:10.1016/s0022-1139(99)00279-1

47. Ahrens, M.; Scholz, G.; Braun, T.; Kemnitz, E. Angew. Chem., Int. Ed. 2013, 52, 5328-5332. doi:10.1002/anie.201300608

48. Luo, Y. Comprehensive Handbook of Chemical Bond Energies; CRC Press: Boca Raton, FL, USA, 2007.

49. Kuehnel, M. F.; Lentz, D.; Braun, T. Angew. Chem., Int. Ed. 2013, 52, 3328-3348. doi:10.1002/anie.201205260

50. Kervarec, M.-C.; Marshall, C. P.; Braun, T.; Kemnitz, E. J. Fluorine Chem. 2019, 221, 61-65. doi:10.1016/j.jfluchem.2019.04.001

51. Xie, Z.; Fan, J.; Cheng, Y.; Jin, L.; Hu, G.; Lu, J.; Luo, M. Ind. Eng. Chem. Res. 2013, 52, 3295-3299. doi:10.1021/ie303067d

52. Wang, H.; Tung, H. S.; Singh, R. R.; Shankland, I. Process for Producing 2,3,3,3-Tetrafluoropropene. U.S. Patent US8,766,020 B2, July 1, 2014.

53. Braun, T.; Wehmeier, F.; Altenhöner, K. Angew. Chem., Int. Ed. 2007, 46, 5321-5324. doi:10.1002/anie.200700711

54. Douvris, C.; Ozerov, O. V. Science 2008, 321, 1188-1190. doi:10.1126/science.1159979

55. Douvris, C.; Nagaraja, C. M.; Chen, C.-H.; Foxman, B. M.; Ozerov, O. V. J. Am. Chem. Soc. 2010, 132, 4946-4953. doi:10.1021/ja100605m

56. Scott, V. J.; Çelenligil-Çetin, R.; Ozerov, O. V. J. Am. Chem. Soc. 2005, 127, 2852-2853. doi:10.1021/ja0426138
57. Panisch, R.; Bolte, M.; Müller, T. J. Am. Chem. Soc. 2006, 128, 9676-9682. doi:10.1021/ja061800y

58. Talavera, M.; Meißner, G.; Rachor, S. G.; Braun, T. Chem. Commun. 2020, 56, 4452-4455. doi:10.1039/d0cc01420f

59. Song, J.-D.; Song, T.-Y.; Zhang, T.-T.; Wang, Y.; Luo, M.-F.; Lu, J.-Q. J. Catal. 2018, 364, 271-281. doi:10.1016/j.jcat.2018.04.014

60. Wang, F.; Liang, Y.; Zhang, W.-X.; Wang, Y.-J.; Lu, J.-Q.; Meng-Fei, L. Indian J. Chem. 2015, 54, 1192-1197.

61. Tung, H. S.; Johnson, R. C.; Merkel, D. C. Process for the Manufacture of 1,3,3,3-Tetrafluoropropene. U.S. Patent US7,592,494 B2, Sept 22, 2009.

62. Pen, S.; Nappa, M. J. Dehydrofluorination of $245 f$ to $1234 z e$. U.S. Patent US9,302,962 B2, April 5, 2016.

63. Burdeniuc, J.; Jedicka, B.; Crabtree, R. H. Chem. Ber. Recl. 1997, 130, 145-154. doi:10.1002/cber.19971300203

64. Müller, T. Silylium Ions. In Functional Molecular Silicon Compounds I. Structure and Bonding; Scheschkewitz, D., Ed.; Springer: Cham, Switzerland, 2013; Vol. 155, pp 107-162. doi:10.1007/430_2013_132

65. Murthy, J. K.; Gross, U.; Rüdiger, S.; Rao, V. V.; Kumar, V. V.; Wander, A.; Bailey, C. L.; Harrison, N. M.; Kemnitz, E. J. Phys. Chem. B 2006, 110, 8314-8319. doi:10.1021/jp0601419

\section{License and Terms}

This is an Open Access article under the terms of the Creative Commons Attribution License (https://creativecommons.org/licenses/by/4.0). Please note that the reuse, redistribution and reproduction in particular requires that the authors and source are credited.

The license is subject to the Beilstein Journal of Organic Chemistry terms and conditions: (https://www.beilstein-journals.org/bjoc)

The definitive version of this article is the electronic one which can be found at: https://doi.org/10.3762/bjoc. 16.213 